\title{
Mental well-being and future career intentions of new graduate nurses and midwives in their first year of entry into the workforce: a cross sectional survey
}

\author{
AUTHORS \\ SE OK OHR RN, B. Nursing, M.Health Management, \\ $\mathrm{PhD}^{1}$ \\ DOREEN HOLM RN/RM, Graduate Certificate \\ Industrial Relations, M. Human Resource \\ Management ${ }^{2}$ \\ JEAN BALL B Math, Grad Dip Med Stats ${ }^{2}$ \\ MARALYN FOUREUR PhD ${ }^{3,4}$ \\ 1 Nursing and Midwifery Research Centre, Hunter New \\ England Local Health District \& School of Nursing and \\ Midwifery, Faculty of Health, University of Newcastle, NSW, \\ Australia \\ 2 Nursing and Midwifery Services, Hunter New England Local \\ Health District, Newcastle, NSW, Australia \\ 3 Nursing and Midwifery Research Centre, Hunter New \\ England Local Health District \& University of Newcastle, \\ NSW, Australia \\ 4 Hunter New England Nursing \& Midwifery Research Centre, \\ Hunter Medical Research, NSW, Australia
}

\section{CORRESPONDING AUTHOR}

SE OK OHR Nursing and Midwifery Research Centre, Hunter New England Local Health District, Gate Cottage, James Fletcher Campus, 72 Watt Street, Newcastle NSW 2300 \& School of Nursing and Midwifery, Faculty of Health, University of Newcastle Australia. Phone: +61 249246724 Email: seok.ohr@health.nsw.gov.au

\section{ABSTRACT}

Objective: To explore mental well-being and future career intentions of new graduate nurses and midwives (NGs) in their first year of work.

Background: Mental well-being is important for people to feel good and function well in their daily life. However, little is known about changes in mental well-being and future workforce intentions of nurses and midwives in their first year of professional practice.

Study design and methods: A cross-sectional study was conducted at a large Local Health District in New South Wales, Australia. Nurses and midwives ( $N=170)$ who commenced a transition program in February 2017 were invited to complete a survey using the Warwick-Edinburgh Mental Well-being Scale after four to six weeks (Group 1) and again at 10-11 months (Group 2). Unpaired t-tests for independent samples were used to compare differences between time-points.

Results: Response rates were 47\% for Group 1 and $29 \%$ for Group 2. The mean (median) mental wellbeing score was 52.1 (52) for Group 1 and 48.7 (50) for Group 2. While the majority of respondents retained a moderate/high sense of well-being, decreases were significant for the items, 'feel relaxed' and 'interested in new things'. Being located in rural areas, being aged between 20-29 years and being female was related to a lower well-being score for Group 2. The main factors contributing to NGs wellbeing were: a supportive environment, resilience, self-efficacy, and sense of achievement. Respondents with higher total well-being scores were significantly more likely to continue working at the current 
organisations and significantly less likely to seek employment in other organisations.

Discussion: This study provides valuable insight into the mental well-being and future career intentions of new graduate nurses and midwives. Most of them retain a moderate to high sense of well-being over their first year of practice which suggests sufficient support is provided, or that they are an inherently resilient population. Building supportive environments that assist resilience, self-efficacy and sense of achievement is critical.

Conclusion: With the current COVID pandemic situation, addressing factors impacting on the mental well-being and future career intentions of new graduate nurses and midwives in their first year may be more critical to enhance job satisfaction, leading to improved workforce resilience and capability and therefore the provision of quality healthcare.

Implications for research, policy and practice: The findings of the study reinforce the importance of mental well-being to retain new graduate nurses and midwives in the future workforce.
What is already known about the topic?

- Positive mental well-being supports people to feel good and function well.

- Entering into a new workforce as a novice practitioner is stressful and maintaining positive mental well-being in the workplace enhances the capacity to provide safe quality healthcare.

- Little is known about changes in mental well-being and future workforce intentions of new graduate nurses and midwives (NGs) in their first year of professional practice.

What this paper adds?

- Findings show that the majority of NGs retained a moderate/high sense of well-being throughout their first year of their professional life.

- Providing a supportive environment, increasing resilience, self-efficacy and sense of achievement will enhance maintenance of positive mental wellbeing and retention of NGs in the workforce.

Key words: Career intentions, mental well-being, new graduate nurses and midwives, transition, workforce

\section{INTRODUCTION}

Nurses and midwives comprise almost $50 \%$ of the health workforce world-wide. ${ }^{1}$ The recruitment and retention of new graduate nurses and midwives (NGs) has been one of the key areas of discussion to promote and sustain the health workforce. ${ }^{1,2}$ With the COVID-19 pandemic, the importance of the nursing and midwifery workforce to the provision of healthcare has been highlighted. ${ }^{3}$ Mental well-being has been acknowledged as a significant factor that can impact the NGs' ability to provide safe, quality care to patients and influence their desire to remain as part of the health workforce. ${ }^{4}, 5$ Staffing challenges are often critical, not only in metropolitan regions, but also in rural and remote areas. ${ }^{2}$ Ensuring a positive sense of mental well-being amongst staff is a vital part of managing the health workforce, and efforts to increase NGs' well-being and gain insight into their future intentions are valuable for strategy formation. ${ }^{5} \mathrm{~A}$ number of studies have revealed that organisational socialisation of NGs in their first year was often related to mental wellbeing. ${ }^{6-8}$ Efforts to improve organisational socialisation such as transition programs for NGs, orientation programs, and personal support were reported in many studies. 9-11 $^{-1}$ However, little is known about changes in mental well-being and future workforce intentions of new graduates in their first year of professional practice. This paper aims to address this gap by inviting beginning practitioners in a large Australian public healthcare organisation to participate in a survey about their well-being and future intentions.

\section{BACKGROUND}

Positive mental well-being enhances the effective functioning of individuals and organisations by allowing individuals to realise their ability to cope with the moderate stresses of life, to work productively and make a contribution to their workplace and profession. ${ }^{4,10,11}$ In health service settings, individual staff well-being enhances the quality of care provided and job satisfaction. ${ }^{10}$ However, the transition into new workplace environments by NGs is characterised as an uneasy journey that can be a stressful experience. ${ }^{12-14}$

A number of different transitioning experiences have been described in attempts to explain the mental/emotional state of NGs in the workforce. Krozek described the psychodynamics of NGs as a mismatch of reality and expectations, overwhelming feelings of incompetence and a lack of confidence. ${ }^{7}$ He further explained that these psychodynamics impact on the behaviour and performance of NGs. These emotions can negatively influence the mental well-being of NGs during the transition into their roles in the health workforce. In developing the theoretical framework of role transition of NGs, Duchscher and Kramer summarised the transition process of NGs into the workforce as one of "transition shock" or "reality shock". 15,16

Several studies have investigated factors that impact the well-being of NGs. Most studies use cross sectional study designs, some use mixed methods and prospective cohort designs. ${ }^{13,18-21}$ A cross sectional study of 420 Canadian NGs 
revealed that three factors influencing NG well-being were job demands (workload), job resources (supportive practice environment), control and personal resources (psychological capital). ${ }^{17}$ Other authors suggested that organisational support and the display of caring behaviours by colleagues positively impacted NGs' mental well-being and influenced their job satisfaction levels. ${ }^{10,22,23}$ However, others suggest that the personality of an individual influences the person's subjective perception of well-being. ${ }^{24,25}$ Damodaran and Raj provided insights that demonstrated individual perceptions such as the meaningfulness of work, competence, helping, supporting and the level of a respectful work community, together with reasonable preconditions of work, were all significant factors that influenced NGs' overall sense of mental well-being. ${ }^{24} \mathrm{~A}$ recent, national cross sectional study of 3,005 Australian nurses and midwives about workplace climate and well-being, indicated experiences of lower engagement in decision-making in work-related concerns and management, impacted on their well-being. ${ }^{5}$ It was also revealed that $25-30 \%$ of nurses and midwives in this study intended to leave their profession, possibly resulting from high levels of workload demand and challenges with managing emotions at work. ${ }^{5}$

Despite increasing discussions about the well-being of NGs, there is limited literature about how the well-being of NGs might change as they transition into the workplace and what effect their well-being may have on their future career movement. The mental well-being of NGs is a concern for healthcare organisations as they are constantly being challenged to maintain a committed, competent and fully functioning workforce, given the nursing and midwifery workforce shortage in Australia. ${ }^{2}$ This has been a cause of concern for the Local Health District (LHD) where this study was undertaken. As a part of sustaining its workforce each year, this LHD recruits more than 215 NGs at 21 metropolitan, rural and remote healthcare settings. They are recruited on a one-year temporary contract with two intakes (usually February and July each year) via the New South Wales (NSW) Health, Transition into Professional Practice (TPP) program. ${ }^{26}$ The TPP is a program to assist NGs to transition into the workforce by providing a range of targeted supports such as an orientation program, supernumerary days, professional development days, and additional support from new graduate coordinators and mentors during 12 months of the TPP as described by Ohr et al. ${ }^{9}$

With the nursing and midwifery workforce crisis, sustaining the mental well-being of NGs during their transition into the workforce may contribute to intentions for career movement. This study was designed to explore and better understand the mental well-being of NGs during their first year of professional practice and their intentions concerning career movement.

\section{STUDY DESIGN AND METHODS}

Design: This study used a cross-sectional design with a survey administered at two time points.

Setting: A geographically large LHD in New South Wales (NSW), Australia that provides health services to over one million people in 21 acute and community healthcare settings in metropolitan, rural and remote locations.

Participants: 170 NGs (155 Nurses and 15 Midwives) who commenced their Transition into Professional Practice program (TPP) in February 2017 were asked to participate in the study which involved completing an online survey about their experiences as a NG.

\section{DATA COLLECTION}

Data were collected via an online survey. A link to the survey was emailed to the NGs at two time periods. The first survey was administered at four to six weeks following commencement of the TPP (Group 1) and the second survey was administered at 10-11 months following commencement (Group 2). Participation was voluntary and completion of the survey was deemed consent to participate.

\section{DATA COLLECTION TOOL: THE SURVEY}

The link to the survey was emailed to the same group of 170 NGs at both time points. The survey responses were anonymous so responses from Group 1 and Group 2 were unable to be linked by respondent.

The first survey included questions relating to the onboarding program used to support NGs as well as a wellbeing assessment scale, the Warwick-Edinburgh Mental Well-Being Scale (WEMWBS). The WEMWBS is a validated tool for the measurement of mental well-being. ${ }^{27-31}$ The second survey included three components: WEMWBS, questions about future intentions after completion of the TPP and the type of tenure (full-time, part-time, or casual) preferred. WEMWBS was used with permission from the authors. ${ }^{27}$ This validated tool was chosen as it was identified as a credible means of monitoring mental well-being at a population level by many authors. ${ }^{28-30}$ The WEMWBS covers both hedonic and eudemonic aspects of mental health including positive affect (feelings of optimism, cheerfulness, and relaxation), satisfying interpersonal relationships and positive function (energy, clear thinking, self-acceptance, personal development, competence and autonomy). ${ }^{27}$ The WEMWBS includes 14 positively worded questions with 5 point Likert-type responses, scoring from 'None of the time' (score 1), up to 'all of the time' (score 5). A higher WEMWBS score indicates a higher level of mental well-being. 
TABLE 1: REPRESENTATIVENESS OF RESPONDENTS

\begin{tabular}{|c|c|c|c|c|}
\hline & & Total NGs $(n=170)$ & Respondents $(n=80)$ & P-value * \\
\hline \multirow[t]{3}{*}{ Age group } & $20-29$ years & $106(63 \%)$ & $53(66 \%)$ & 0.5 \\
\hline & $30-39$ years & $38(22 \%)$ & $19(24 \%)$ & 0.8 \\
\hline & $40+$ years & $26(15 \%)$ & $8(10 \%)$ & 0.3 \\
\hline \multirow[t]{2}{*}{ Gender } & Male & $11(6 \%)$ & $2(3 \%)$ & 0.2 \\
\hline & Female & $159(94 \%)$ & $78(98 \%)$ & 0.2 \\
\hline \multirow[t]{2}{*}{ Location of employment } & Metropolitan & $115(68 \%)$ & $43(54 \%)$ & 0.04 \\
\hline & Rural & $55(32 \%)$ & $37(46 \%)$ & 0.03 \\
\hline
\end{tabular}

* p-value of difference between Total NGs and respondents

\section{DATA ANALYSIS}

The 14 individual item responses to the well-being questions were summed to create an overall total score per respondent, ranging from 14 to 70 . Overall total scores were categorised according to the Santini et al. interpretation, ${ }^{31}$ as follows:

- $\leq 43$ : low sense of well-being

- $>$ 43- $\leq 60$ : moderate sense of well-being

- >60: high sense of well-being.

Overall mean scores were calculated for each time-point. Item mean scores were calculated for each of the 14 well-being items at each time-point.

Quantitative data were analysed using descriptive statistics and by comparing differences between Time 1 responses (Group 1) and Time 2 responses (Group 2) using inferential statistics (unpaired t-test for independent samples).

Qualitative data (text data of the survey such as reasons given for their scores) were analysed by content analysis.32

\section{ETHICAL CONSIDERATIONS}

Approval to conduct this study was granted by the LHD Ethics Committee (HNEHREC Reference No:16/12/14/5.14). Confidentiality was ensured by the survey being completed anonymously online.

\section{RESULTS}

One hundred and seventy NGs were invited to participate in the project. There were 8 o completed responses (47\%) at Time 1 (Group 1) and 44 completed responses (29\%) at Time 2 (Group 2). The response rate for Group 2 was calculated after excluding 17 invitation emails which bounced back as "not deliverable".

\section{REPRESENTATIVENESS AND CHARACTERISTICS OF RESPONDENTS}

Table 1 shows no difference in representativeness of survey respondents compared with total NGs for age group and gender. A significant difference was noted in location of employment, with more survey respondents in rural areas and fewer survey respondents in metropolitan areas than the total NGs ( $\mathrm{p}=0.035)$.

As seen in Table 2 characteristics of respondents in Groups 1 and 2, there were no significant differences in age group, gender, employment location (rural/metropolitan) and years of experience. There was a significant difference between respondents who had prior nursing/midwifery experience between Groups 1 and 2, with fewer respondents with prior nursing/midwifery experience in Group 2 ( $\mathrm{p}=0.045)$.

\section{MENTAL WELL-BEING ASSESSMENT}

Mean (median) WEMWBS was 52.1 (52) for Group 1 and 48.7 (50) for Group 2 (mean difference $=3.4$, p-value for difference in mean scores $=0.02$ ). The number of NGs with low wellbeing score increased from $9 \%$ in Group 1 to $34 \%$ in Group 2. For Group 1, 91\% $(n=73)$ of the respondents rated their total well-being assessment as above 44 (moderate to high wellbeing scores), compared with $66 \%(n=29)$ who scored above 44 in Group 2 (See Figure 1).

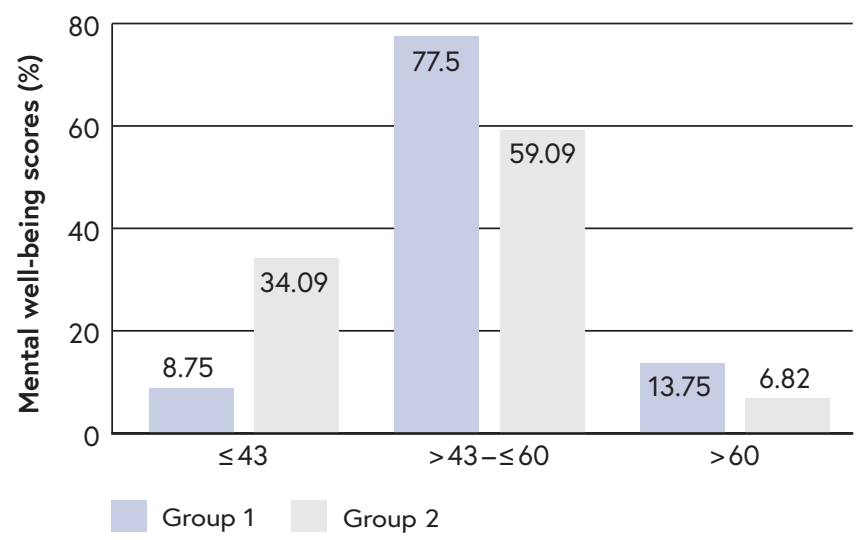

FIGURE 1: OVERALL TOTAL MENTAL WELL-BEING SCORES 
TABLE 2: CHARACTERISTICS OF RESPONDENTS

\begin{tabular}{|c|c|c|c|c|}
\hline & & Group $1(n=80)$ & Group $2(n=44)$ & P-value * \\
\hline \multirow[t]{3}{*}{ Age group } & $20-29$ years & $53(66 \%)$ & $30(68 \%)$ & \multirow[t]{3}{*}{0.4} \\
\hline & $30-39$ years & $19(24 \%)$ & $7(16 \%)$ & \\
\hline & $40+$ years & $8(10 \%)$ & $7(16 \%)$ & \\
\hline \multirow[t]{2}{*}{ Gender } & Male & $2(3 \%)$ & $2(5 \%)$ & \multirow[t]{2}{*}{0.6} \\
\hline & Female & $78(98 \%)$ & $42(95 \%)$ & \\
\hline \multirow[t]{2}{*}{ Location of employment } & Metropolitan & $43(54 \%)$ & $24(55 \%)$ & \multirow[t]{2}{*}{0.9} \\
\hline & Rural & $37(46 \%)$ & $20(45 \%)$ & \\
\hline \multirow[t]{2}{*}{ Prior N/M experience } & Yes & $60(75 \%)$ & $22(50 \%)$ & \multirow[t]{2}{*}{0.045} \\
\hline & No & $20(25 \%)$ & $22(50 \%)$ & \\
\hline \multirow[t]{3}{*}{ Years of experience } & $<1$ year & $19(32 \%)$ & $7(32 \%)$ & \multirow[t]{3}{*}{0.3} \\
\hline & $1-3$ years & $28(47 \%)$ & $5(23 \%)$ & \\
\hline & $>3$ years & $13(22 \%)$ & $10(45 \%)$ & \\
\hline
\end{tabular}

${ }^{*} p$-value of difference between groups 1 and 2

\section{ELEMENTS OF WELL-BEING ASSESSMENT}

Table 3 shows that mean well-being scores of each item declined from the Group 1 scores to the Group 2 scores on every individual item. The summary scores significantly decreased from 3.1 to 2.9 ( $95 \%$ CI, P-value $=0.04$ ) from Group 1 to Group 2. This decrease was significant for two of the individual items, 'feel relaxed' $(\mathrm{p}=0.02)$ and 'interested in new things' $(p=0.03)$.

\section{ASSOCIATION OF FACTORS WITH WELL-BEING SCORES}

Despite the overall total well-being scores being within the moderate range of well-being for both groups, there were no significant differences in total well-being scores between Group 1 and Group 2 for those with prior nursing/midwifery experience, nor for the number of years of prior experience. However, there was a highly significant decrease in overall total well-being score for respondents aged 20-29 years ( $\mathrm{p}=0.03)$, being female $(\mathrm{p}=\mathrm{0.03})$ and located in rural locations, between Group 1 and Group $2(\mathrm{p}<0.01)$.

TABLE 3: MEAN MENTAL WELL-BEING ITEM SCORES

\begin{tabular}{|c|c|c|c|c|}
\hline & \multicolumn{2}{|c|}{ Mean score $(95 \% \mathrm{Cl})$} & \multirow{2}{*}{$\begin{array}{r}\text { Mean } \\
\text { difference }\end{array}$} & \multirow[t]{2}{*}{ P-value * } \\
\hline & Group $1(n=80)$ & Group $2(n=44)$ & & \\
\hline I've been feeling optimistic about the future & $3.9(3.7,4.1)$ & $3.6(3.3,3.9)$ & -0.3 & 0.07 \\
\hline I've been feeling useful & $4(3.8,4.1)$ & $3.8(3.5,4)$ & -0.2 & 0.33 \\
\hline I've been feeling relaxed & $3.2(3,3.4)$ & $2.8(2.6,3.1)$ & -0.4 & 0.02 \\
\hline I've been feeling interested in other people & $4.1(3.9,4.2)$ & $3.8(3.5,4.1)$ & -0.3 & 0.12 \\
\hline I've had energy to spare & $3(2.7,3.2)$ & $2.8(2.5,3.1)$ & -0.2 & 0.4 \\
\hline I've been dealing with problems well & $3.8(3.6,3.9)$ & $3.6(3.4,3.8)$ & -0.2 & 0.24 \\
\hline I've been thinking clearly & $3.9(3.7,4)$ & $3.7(3.5,3.9)$ & -0.2 & 0.16 \\
\hline I've been feeling good about myself & $3.8(3.6,3.9)$ & $3.5(3.2,3.7)$ & -0.3 & 0.05 \\
\hline I've been feeling confident & $3.6(3.4,3.8)$ & $3.5(3.2,3.7)$ & -0.1 & 0.64 \\
\hline I've been feeling close to other people & $3.6(3.5,3.8)$ & $3.3(3,3.6)$ & -0.3 & 0.09 \\
\hline I've been able to make up my own mind about things & $3.9(3.7,4.1)$ & $3.7(3.4,3.9)$ & -0.2 & 0.11 \\
\hline I've been feeling loved & $3.5(3.3,3.7)$ & $3.4(3.1,3.8)$ & -0.1 & 0.82 \\
\hline I've been interested in new things & $4.1(3.9,4.2)$ & $3.7(3.5,4)$ & -0.3 & 0.03 \\
\hline I've been feeling cheerful & $3.8(3.7,4)$ & $3.5(3.2,3.8)$ & -0.3 & 0.06 \\
\hline Summary score & $3.1(3,3.2)$ & $2.9(2.7,3.1)$ & -0.2 & 0.04 \\
\hline
\end{tabular}

* unpaired t-tests for independent samples 
TABLE 4: ASSOCIATION OF FACTORS WITH WELL-BEING SCORES [NB: NOT REFERRED TO IN TEXT]

\begin{tabular}{|c|c|c|c|c|}
\hline & & \multicolumn{2}{|c|}{ Mean total scores $(95 \% \mathrm{Cl})$} & \multirow[t]{2}{*}{ P-value * } \\
\hline & & Group 1 & Group 2 & \\
\hline \multirow[t]{3}{*}{ Age group } & $20-29$ years & $51(49,53)$ & $47(44,50)$ & 0.03 \\
\hline & 30-39 years & $55(51,59)$ & $49(42,56)$ & $>0.05$ \\
\hline & $40+$ years & $53(45,60)$ & $54(44,65)$ & $>0.05$ \\
\hline \multirow[t]{2}{*}{ Gender } & Female & $52(50,54)$ & $49(46,51)$ & 0.03 \\
\hline & Male & $56(* \star)$ & $\left.511^{(\star}\right)$ & ** \\
\hline \multirow[t]{2}{*}{ Prior NM experience } & Yes & $52(50,54)$ & $50(46,54)$ & $>0.05$ \\
\hline & No & $53(50,57)$ & $48(44,51)$ & $>0.05$ \\
\hline \multirow[t]{2}{*}{ Years of experience } & $<1$ year & $51(47,55)$ & $49(43,55)$ & $>0.05$ \\
\hline & $1-3$ years & $51(48,53)$ & $48(35,61)$ & $>0.05$ \\
\hline \multirow[t]{2}{*}{ Location of employment } & Metropolitan & $52(49,54)$ & $51(47,54)$ & $>0.05$ \\
\hline & Rural & $52(50,55)$ & $46(42,51)$ & $<0.01$ \\
\hline
\end{tabular}

* unpaired t-tests for independent samples

** Could not be calculated due to small sample size

Additional comments provided by the NGs (Group 1: $\mathrm{n}=11$, Group 2: $n=15$ ) identified three main reasons for their well-being rating and those suggested were supportive environments, resilience and self-efficacy, and sense of achievement.

\section{SUPPORTIVE ENVIRONMENT}

The respondents stated that they found the early period of their work was "extremely stressful" (Metropolitan area). Six respondents commented that a supportive environment was one reason for their scores of well-being at the initial stage of their professional work.

"Having supportive and encouraging staff on the ward has been absolutely enormous (crucial really) in my well-being. They celebrate small victories with me and offer support during tough situations." (Group 1, Metropolitan area, Moderate well-being)

"Feeling as though the ward appreciates, accepts and supports you makes a huge difference to your well-being and contribution to the workforce." (Group 1, Metropolitan area, Moderate well-being)

"Supernumerary shifts are important and useful, however on a ward base level its essential they are pairing new staff with approachable individuals who understand it's a nerve-racking experience and we are trying to build our confidence as new RNs.”(Group 1, Metropolitan area, Moderate well-being)

Furthermore, all six respondents from rural areas and one from a metropolitan area in Group 2 identified an unsupportive environment, lack of authentic leadership, bullying and a lack of learning opportunities as the main reasons for their scores.
"Very stressful at wards, a lot of personalities to contend with as well as some bullying and discrimination. Not enough staff at times and no support from managers to help with same." (Group 2, Rural area, Moderate well-being)

"As a new graduate midwife I was unsupported at the hospital ...by the educators and manager. I don't ever remember the educators introducing themselves to me. In fact, they often ignored me and only spoke to me when they wanted to tell me I'm doing something wrong which was often in front of patients. I felt bullied and ostracised. The only support I received was from the midwives who weren't educators or put in a position to support me. I often went to the manager and explained what was happening and she told me "I can see we are breaking you down" and didn't make any changes. I also told the manager about one particular educator who was yelling at me in front of patients and the manager said "we have no tolerance for bullying but if you treat her like she is your mother she will mother you". I felt trapped and was becoming depressed." (Group 2, Rural area, Low well-being)

"Learning opportunities came from the time spent with Clinical Nurse Educators. When funding has been cut from providing an educator for XX wards, learning experiences were rushed by the staff on the shift." (Group 2, Metropolitan area, Moderate well-being)

More than 37\% of the respondents in Group 2 were mature age nurses and midwives. The comments by these respondents indicated they felt that they were discriminated against due to their age.

"The younger staff made me feel as though I was past my 'useby' date and had no place in their organisation. There were comments about older staff being 'set in their ways' and not moving with the times. These comments were made during my 
orientation-before I even had a chance to show them my own skills or lack thereof!" (Group 2, Rural area, Low well-being)

"The nursing staff took an instant dislike to me and would not assist me at all. I did my best and worked hard, but I felt because of my white hair, I was doomed from the start." (Group 2, Rural area, Low well-being)

\section{RESILIENCE AND SELF-EFFICACY}

Eleven comments were related to personal resilience and selfefficacy that was required to help cope with the transition process into the work environment and being resilient and confident contributed positively to their well-being.

"I have found it really hard to have a work/life balance. Working full time and being engaged all of the time is exhausting. After I leave work I hardly have the energy to do anything at home as I need to recover from the day and rest. Sometimes I feel like I burn the candle at both ends by doing too much. Taking the time out for ourselves is so important and needs to be a high priority, we need to make time for ourselves." (Group 1, Rural area, Moderate well-being)

"I think this is personal...some people are more confident than others...some like me set too high of a standard for themselves so found it very difficult while learning how to best care for patients under my care to complete all the tasks required on time.”(Group 1, Rural area, Moderate well-being)

"As I started my first rotation in the HDU [ high dependency unit], I felt very overwhelmed however I have gained confidence as I have realised my abilities and been offered excellent support by other staff." (Group 1, Metropolitan area, High wellbeing)

\section{SENSE OF ACHIEVEMENT}

Four respondents from metropolitan areas at Group 2 talked about their sense of achievement as a significant reason for their current mental well-being.

"I feel that this year has taught me how to appropriately deal with new issues and problems, I know who to ask for information and education and where to look up policies and procedures." (Group 2, Metropolitan area, Moderate well-being)

"I finally feel like my future has started since finishing university and that I am a real adult - it feels good." (Group 2, Metropolitan area, Moderate well-being)

\section{FUTURE INTENTIONS OF GROUP 2}

As the Group 2 survey was conducted at the end of the first year of the professional work, the NGs were asked about their intention for future career movement. As Table 4 describes, 40 respondents (91\%) said that they were likely to continue working in their current LHD. Despite this, 13 respondents (30\%) stated that they would look for a job outside of the current LHD. Respondents with higher overall total well- being scores indicated that they were more likely to stay at their current workplace ( $\mathrm{p}=0.028$ ) and were significantly less likely to seek employment in another LHD or the private sector ( $\mathrm{p}<\mathrm{0} .01)$. Only $14 \%$ of respondents indicated their intention to leave the nursing or midwifery profession. Seventy per cent of respondents were interested in pursuing employment in speciality or critical care areas or pursuing a 2nd year professional practice position. Eighty per cent of respondents in rural areas and $38 \%$ of respondents in metropolitan areas showed a willingness to remain in their current geographical areas and 70\% of respondents indicated they wanted permanent full-time tenure.

\section{TABLE 5: NGS FUTURE INTENTIONS ( $\mathrm{N}=44)$}

\begin{tabular}{|l|r|r|r|}
\hline Intention & $\begin{array}{r}\text { Likely/ } \\
\text { Very Likely }\end{array}$ & Neutral & $\begin{array}{r}\text { Unlikely/ } \\
\text { Very } \\
\text { unlikely }\end{array}$ \\
\hline Work at current LHD & $91 \%(40)$ & $0 \%(0)$ & $9 \%(4)$ \\
\hline $\begin{array}{l}\text { Seek employment outside } \\
\text { the current LHD }\end{array}$ & $30 \%(13)$ & $34 \%(15)$ & $36 \%(16)$ \\
\hline Leave profession & $14 \%(9)$ & $9 \%(4)$ & $77 \%(34)$ \\
\hline $\begin{array}{l}\text { Seek employment in } \\
\text { speciality or critical areas }\end{array}$ & $74 \%(32)$ & $14 \%(6)$ & $14 \%(6)$ \\
\hline $\begin{array}{l}\text { Seek employment in } \\
\text { general areas }\end{array}$ & $48 \%(21)$ & $18 \%(8)$ & $34 \%(15)$ \\
\hline $\begin{array}{l}\text { Willingness to work in } \\
\text { rural/remote areas }\end{array}$ & $57 \%(25)$ & $25 \%(11)$ & $18 \%(8)$ \\
\hline $\begin{array}{l}\text { Seek a 2nd year transition } \\
\text { to professional practice } \\
\text { position }\end{array}$ & $66 \%(29)$ & $9 \%(4)$ & $25 \%(11)$ \\
\hline
\end{tabular}

\section{DISCUSSION}

The findings of this study suggest that the overall total wellbeing scores of the majority of respondents were within the moderate or high range for both groups: Time 1 responses (Group 1) and Time 2 responses (Group 2). However it is a concern that more than a third of the respondents (34\%) in Group 2 had low well-being scores. While some authors described NGs as having transition shock, and experiencing stress and challenges in the beginning of their first year of practice, the moderate to high well-being scores among Group 1 in our study may have been influenced by the NGs' excitement about securing employment or their euphoric state of becoming a professional nurse or midwife. ${ }^{15,25,33}$ However, a decrease of well-being scores in the later stage of the first year of entering the workforce in Group 2 could be attributed to the need to look for future employment, as most contracts had temporary employment tenure. 33,34 Other reasons may be a lack of professional opportunities or the burnout that some NGs experienced during their work life as explained by a study of 1,228 nurses from Australia and the USA..$^{21,22}$ Further, mental well-being could be affected by the nature of nurses' and midwives' work which is acknowledged as physically and emotionally demanding.5, 25,35 
Similar to Päätalo and Kyngäs and Holland et al., both organisational and personal factors that influenced the well-being of NGs were identified., 5 The well-being of NGs was influenced by a negative environment such as one in which bullying, discrimination, offensive behaviours, and inadequate personal support were present. Building a supportive and respectful workplace may enhance the well-being of NGS. Further, as asserted by Gruman and Saks, well-being was also influenced by an individual's resilience, self-efficacy and a sense of achievement. ${ }^{11}$ Building resilience and self-efficacy may provide NGs with greater ability to act and perform tasks and to recover from challenges such as adversity, uncertainty, failure and overwhelming changes that they face. ${ }^{23}$ Increasing well-being may enhance resilience and mental health. ${ }^{36,37}$ Understanding the psychodynamic coping strategies of NGs and improving organisational socialisation may make a difference in the success of the transition and well-being of NGs. ${ }^{7,11}$ As suggested by Thomas and Revell, building resilience and self-efficacy of nurses and midwives requires support, time and empowerment. $3^{8}$ The strategies for increasing these factors should be considered in the LHD strategies to improve the well-being of NGs, particularly focusing on those in younger age groups and located in rural areas.

This becomes paramount when aiming to increase the sustainability of the nursing and midwifery workforce which can present its own challenges, especially in rural areas. With organisational socialisation being emphasised as a crucial component to assist new employees to transition into the workforce, assisting a better socialisation among NGs may improve their well-being. ${ }^{939-41}$ Organisational strategies such as orientation programs, personal support by mentors and managers throughout the first year of their professional life remain important in enabling NGs to maintain a positive sense of well-being. This in turn may support the longterm sustainability of the LHD workforce. ${ }^{6,7,9}$ Furthermore, other strategies such as allocating responsibilities to match the skill set of NGs, acknowledging them as beginner practitioners, and encouraging a sense of "a job well done" may assist their transition, and improve their well-being. Increased NG well-being in their first year of professional practice may increase the ability of health services to foster better career planning and may contribute to a lower turnover of NGs in the future. $4^{40,41}$

Further research about understanding the mental well-being of new graduate nurses and midwives during the COVID pandemic is needed if we are to continue to develop effective strategies to sustain the Australian nursing and midwifery workforce.

\section{LIMITATIONS AND STRENGTHS OF THE STUDY}

The findings of this study may not be generalised to NGs in other LHDs as the study population was small and sourced from only one LHD in NSW, Australia. While the difference in well-being scores between Group 1 and Group 2 was statistically significant it is important to note that the scores remained in the moderate mental well-being range, therefore the noted change may be of limited clinical significance. The survey method may have limited the insights gained from this study as respondents only had opportunities to provide written responses to open-ended questions. Methods such as individual interviews or focus groups would have been beneficial for further investigation of the reasons for the well-being scores. Despite the limitations, this study presents new knowledge about the mental well-being of new graduate nurses and midwives in different stages of their first professional year.

\section{CONCLUSION}

This study has provided further insight into changes in the mental well-being of NGs as they transition into professional practice and adds to the body of knowledge in this area. This study identified a deterioration in well-being between Group 1 and Group 2 despite being recruited to a specially developed transition to professional practice program. Understanding the needs of this workforce group and the impact their future career intentions can have on workforce sustainability is critical. Further investigation into the well-being of NGs and further development of strategies to promote wellbeing and future retention of nurses and midwives is highly recommended. The need to provide ongoing and highquality support to enhance NGs' well-being and facilitate higher levels of professional capability was highlighted. Policy makers, educators and healthcare managers need to act on a notion that organisational support is paramount in building resilience and self-efficacy of NGs and sustaining a positive sense of well-being. These are the key elements to improving the capability of the nursing and midwifery workforce, increasing job satisfaction for NGs and promoting the delivery of quality healthcare.

Acknowledgements The authors would like to thank all new graduate nurses and midwives who participated in this study.

Declaration of conflicting interests: All authors declare that they have no conflict of interest in relation to this work.

Funding support: No funding was received for the conduct or write up of this work. 


\section{REFERENCES}

1. World Health Organization. Health workforce: Nursing and Midwifery. 2019. [cited 2019 Feb 1] Available from: Available from: https://www.who.int/hrh/nursing midwifery/en/

2. Health Workforce Australia (HWA). Health Workforce 2025 - Doctors, Nurses and Midwives. 2012. [cited XXXX XXX XX] Available from: https://apo.org.au/sites/default/files/resourcefiles/2012-01/apo-nid154456.pdf

3. International Council of Nurses (ICN). The Globle Nursing shortage and nurse retention: Internatinal Council of Nurses. Internaitonal Council of Nurses. Geneva. 2022. [cited 2021 Aug 23]. Available from https://www.icn.ch/system/files/2021-07/ ICN\%20Policy\%20Brief Nurse\%20Shortage\%20and\%20 Retention.pdf

4. Sears LE, Shi Y, Coberley CR, Pope JE. Overall well-being as a predictor of health care, productivity, and retention outcomes in a large employer. Popul Health Manag. 2013;16(6):397-405.

5. Holland PJ, Tham TL, Gill FJ. What nurses and midwives want: findings from the national survey on workplace climate and well-being. Int J Nurs Pract. 2018;24(3):e12630.

6. Chachula K, Myrick F, Yonge O. Letting go: how newly graduated registered nurses in Western Canada decide to exit the nursing profession Nurse Educ Today. 2015;35:912-8.

7. Krozek C. Psychodynamics of onboarding new graduate nurses. J Contin Edu Nurs. 2017;48(7):299-301.

8. Regan $S$, Wong $C$, Laschiniger $H$, Cummings $G$, Leiter $M$, Macphee M, et al. Starting out: qualitative perspectives of new graduate nurses and nurse leaders on transition to practice. J Nurs Manag. 2019;25(4):246-55

9. Ohr SO, Holm D, Giles M. The organisational socialisation of new graduate nurses and midwives at three months of their entrance into the health workforce. Aust J Adv Nurs. 2020;37(2):3-10.

10. Saeed PS, Ashraf SA, Hamid SN. Mediating role of psychological well-being in the relationship between organizational support and nurses' outcomes: a cross-sectional study. J Adv Nurs. 2018;74(4):887-9

11. Gruman JA, Saks AM. Organizational socialization and newcomers' psychological capital and well-being. In: Arnold BB, editor. Advances in Positive Organizational Psychology. Advances in Positive Organizational Psychology. Emerald Group Publishing Limited; 2013; 211-36.

12. Walker A, Costa B, Foster A, deBruin RL. Transition and integration experiences of Australian graduate nurses: a qualitative systematic review. Collegian. 2017;24:505-12.

13. Parker V, Giles M, Lantry G, McMillan M. New graduate nurses' experiences in their first year of practice. Nurse Educ Today. 2014;34(1):150-6.

13. Calleja P, Adonteng-Kissi B, Romero B. Transition support for new graduate nurses to rural and remote practice: a scoping review. Nurse Educ Today. 2019;76:8-20.

15. Duchscher JEB. Transition shock: the initial stage of role adaptation for newly graduated registered nurses. J Adv Nurs 2009;65(5):1103-13

16. Kramer M. Reality shock: why nurses leave nursing. St. Louis: Mosby Co.; 1974.

17. Spence Laschinger HK, Fida R. New nurses burnout and workplace wellbeing: the influence of authentic leadership and psychological capital. Burn Res. 2014;1(1):19-28.
18. Sharif SP, Ahadzadeh AS, Nia HS. Mediating role of psychological well-being in the relationship between organizational support and nurses' outcomes: a cross-sectional study. J Adv Nurs. 2018;74(4):887-99.

19. Brunetto $Y$, Xerri M, Shriberg A, Farr-Wharton R, Shacklock K, Newman S, et al. The impact of workplace relationships on engagement, well-being, commitment and turnover for nurses in Australia and the USA. J Adv Nurs. 2013;69(12):2786-99.

20. Rush KL, Adamack M, Gordon J, Janke R, Ghement IR. Orientation and transition programme component predictors of new graduate workplace integration. J Nurs Manag. 2015;23(2):143-55.

21. Clausen T, Hogh A, Carneiro IG, Borg V. Does psychological well-being mediate the association between experiences of acts of offensive behaviour and turnover among care workers? A longitudinal analysis. J Adv Nurs. 2013;69(6):1301-13.

22. Lin P, Viscardi M, McHugh M. Factors influencing job satisfaction of new graduate nurses participating in nurse residency program: a systematic review. J Contin Edu Nurs. 2014;45(10):439-52.

23. Stam LMP, Laschinger HKS, Regan S, Wong CA. The influence of personal and workplace resources on new graduate nurses' job satisfaction. J Nurs Manag. 2015;23(2):190-9.

24. Damodaran DK, Raj MJ. Influence of personality dimensions on subjective well-being of nurses. Int J Nurs Edu. 2013;5(2):51-5.

25. Päätalo K, Kyngäs H. Well-being at work: graduating nursing students' perspective in Finland. Contemp Nurse. 2016;52(5):576-89.

26. Ohr SO, Holm D. Evaluation of the transition of new graduate nurses and midwives in HNELHD. Unpublished. 2018.

27. Tennant R, Hiller L, Fishwick R, Platt P, Joseph S, Weich S, et al The Warwick-Edinburgh Mental Well-being Scale (WEMWBS). Health Qual Life Out. 2007;5(63):1-13.

28. Lloyd K, Devine P. Psychometric properties of the WarwickEdinburgh Mental Well-being Scale (WEMWBS) in Northern Ireland. J Mental Health. 2012;21(3):257-63.

29. McKay M, Andretta J. Evidence for the psychometric validity, internal consistency and measurement invariance of Warwick Edinburgh Mental Well-being Scale Scores in Scottish and Irish adolescents. Psychiatry Res. 2017:255-386.

30. Clarke A, Friede T, Putz R, Ashdown J, Martin S, Blake A, et al. Warwick-Edinburgh Mental Well-being Scale (WEMWBS): validated for teenage school students in England and Scotland. A mixed methods assessment BMC Public Health. 2011;11:487.

31. Santini ZI, Stougaard S, Koyanagi A, Ersbøll AK, Nielsen L,

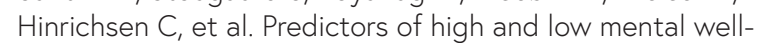
being and common mental disorders: findings from a Danish population-based study. Eur J Public Health. 2020.

32. Erlingsson C, Brysiewicz P. A hands-on guide to doing content analysis. Afr J Emerg Med. 2017;7:93-9.

33. Tuckett A, Eley R, Ng L. Transition to practice programs: what Australian and New Zealand nursing and midwifery graduates said. a graduate eCohort sub-study. Collegian 2017;24:101_8.

34. Mammen B, Hills D, Lam L. Newly qualified graduate nurses' experiences of workplace incivility in Australian hospital settings. Collegian. 2018.

35. Cleary M, Kornhaber R, Thapa D, West S, Visentin S. The effectiveness of interventions to improve resilience among health professionals: a systematic review. Nurse Educ Today. 2018:71:247-63 
36. Gao T, Ding X, Chai J, Zhang Z, Zhang H, Kong Y, et al. The influence of resilience on mental health: the role of general well-being. Int J Nurs Pract. 2017;23(3):e12535.

37. Mills J, Woods C, Harrison H, Chamberlain-Salaun J, Spencer B. Retention of early career registered nurses: the influence of self-concept, practice environment and resilience in the first five years post-graduation. J Res Nurs. 2017;22(5):372-85.

38. Thomas $L$, Revell $S$. Resilience in nursing students: an integrative review. Nurse Educ Today. 2016;36:457-62.

39. Bauer TN. Onboarding new employees: maximizing success. SHRM Foundation's Effective Practice Guideline Series. 2011. [cited 2018 Jul 12] Available from: https://www.shrm.org/ foundation/ourwork/initiatives/resources-from-past-initiatives/ Documents/Onboarding\%20New\%20Employees.pdf.

40. Phillips C, Esterman A, Kenny A. The theory of organisational socialisation and its potential for improving transition experiences for new graduate nurses. Nurse Educ Today. 2015;35(1):118-24

41. Phillips C, Kenny A, Esterman A, Smith C. A secondary data analysis examining the needs of graduate nurses in their transition to a new role. Nurse Educ Pract. 2014;14(2):106-11. 